\title{
Tumor Necrosis Factor- $\alpha$ and Interleukin-6: Potential Interorgan Inflammatory Mediators Contributing to Destructive Periodontal Disease in Obesity or Metabolic Syndrome
}

\author{
Roozbeh Khosravi, ${ }^{1}$ Khady Ka, ${ }^{1}$ Ting Huang, ${ }^{1}$ Saeed Khalili, ${ }^{1,2}$ Bich Hong Nguyen, ${ }^{3}$ \\ Belinda Nicolau, ${ }^{1}$ and Simon D. Tran ${ }^{1}$ \\ ${ }^{1}$ Faculty of Dentistry, McGill University, 3640 University Street, M43, Montreal, Quebec, Canada H3A 0C7 \\ ${ }^{2}$ University of Toronto, Toronto, Canada \\ ${ }^{3}$ Department of Pediatrics, CHU Sainte-Justine, University of Montreal, 3175 Cote-Ste-Catherine, Montreal, Quebec, Canada H3T $1 C 5$
}

Correspondence should be addressed to Simon D. Tran; simon.tran@mcgill.ca

Received 23 April 2013; Revised 2 July 2013; Accepted 2 July 2013

Academic Editor: Massimo Collino

Copyright ( 2013 Roozbeh Khosravi et al. This is an open access article distributed under the Creative Commons Attribution License, which permits unrestricted use, distribution, and reproduction in any medium, provided the original work is properly cited.

Obesity has become a worldwide health burden in the last two decades. Obesity has been associated with increased comorbidities, such as coronary artery disease, diabetes, and destructive periodontal disease. Obesity is also part of a group of risk factors occurring together in an individual, which is referred to as metabolic syndrome. Clinical studies have shown higher risk for destructive periodontal disease in obesity and metabolic syndrome. However, the role of obesity and metabolic syndrome in the onset and development of destructive periodontal disease has not yet been fully understood. In this review, we discuss a working model, which focuses on interorgan inflammation as a common etiological factor for destructive periodontal disease associated with obesity and metabolic syndrome. Specifically, we suggest that elevated levels of tumor necrosis factor- $\alpha$ (TNF- $\alpha$ ) or interleukin 6 (IL-6) both adipokines and known risk factors for destructive periodontal disease-in obesity and metabolic syndrome contribute to the onset and development of destructive periodontal disease. The connections between destructive periodontal disease and systemic conditions, such as obesity or metabolic syndrome, are complex and potentially multidirectional. This review largely focuses on TNF- $\alpha$ and IL-6, inflammatory mediators, as potential common risk factors and does not exclude other biological mechanisms.

\section{Periodontal Diseases}

Periodontal diseases are inflammatory diseases affecting the surrounding and supporting tissues of teeth-the periodontium. Gingivitis and destructive periodontal disease (periodontitis) are the two most common forms of periodontal diseases. Gingivitis is an inflammatory reaction often induced by the pathogens residing in dental plaque (biofilm), which forms on the adjacent tooth surfaces [1]. Destructive periodontal disease results in an apical loss of epithelial attachment along with the periodontal soft and hard tissues [2]. Unlike gingivitis, which is cured following the removal of local etiological factors, destructive periodontal disease is irreversible. Destructive periodontal disease is mediated by various intrinsic and acquired factors; two individuals with similar microbiological profile could show different susceptibility to periodontal diseases [3]. Several case-control and cohort studies have reported the contribution of systemic conditions and diseases in the onset and exacerbation of destruction periodontal disease. Preterm birth [4], cardiovascular diseases [5], and diabetes [6] are examples of these conditions. In addition, a growing body of evidence during the last decade suggests obesity as a risk factor for destructive periodontal disease $[7,8]$. Metabolic syndrome has also been shown to be positively associated with destructive periodontal disease [9-22]. Although the majority of studies on destructive periodontal disease in individuals with obesity or metabolic syndrome concentrated on adults, some studies reported on evidence proposing that this potential link in children and adolescence exists [23]. In this paper, we review 
the evidence suggesting that destructive periodontal disease is linked to obesity and metabolic syndrome, as an example of interorgan crosstalk under inflammatory conditions. Additionally, we discuss a working biological model on the onset of destructive periodontal disease in individuals with obesity or metabolic syndrome based on elevated levels of tumor necrosis factor- $\alpha$ (TNF- $\alpha$ ) and interleukin 6 (IL-6) in these conditions.

\section{Obesity}

Obesity is a multifactorial condition with a wide range of etiological factors including genetic, biological, social, and behavioral factors, all of which likely interact to ultimately lead to a chronic imbalance between energy intake and energy expenditure. This imbalance could cause excessive fat accumulation and result in adverse health consequences. Obesity has reached epidemic proportion worldwide, largely because of increased consumption of high caloric diet and a sedentary lifestyle. According to the World Health Organization [24], approximately 2.3 billion adults will be overweight and more than 700 million will be obese by 2015 . This phenomenon affects particularly developed countries. Over the past two decades, the overall obesity rates have reached $24.1 \%$ and $34.4 \%$ in Canada and the United States, respectively [25].

Based on current Health Canada guidelines, a body mass index (BMI, $\mathrm{kg} / \mathrm{m}^{2}$ ) of 25-30 and over 30 are considered overweight and obese, respectively [26]. Obesity is categorized into 3 classes according to the increased health risks associated with increasing BMI levels: class I (BMI 30-34.9), class II (BMI 35-39.9), and class III (BMI $\geq 40)$ [27]. Pediatric obesity has also become a public health concern since it is more common for children to experience the negative health consequences of obesity, which used to be only seen in adulthood. In 2010, more than 40 million children under the age of five were estimated to be overweight worldwide [28]. In 2004, 26\% of Canadian children and adolescents aged 2 to 17 years were overweight or obese [29]. Obesity has been associated with a wide spectrum of comorbidities, such as coronary artery disease, strokes, diabetes, arthritis, reproductive dysfunctions, and various cancers [30].

\section{Metabolic Syndrome}

Metabolic syndrome is a cluster of risk factors (abdominal obesity, diabetes, high cholesterol, high blood pressure, and raised fasting glucose) that increases the chance of developing type 2 diabetes and cardiovascular diseases [31]. Metabolic syndrome is also known as syndrome $\mathrm{X}$, insulin resistance syndrome, dysmetabolic syndrome X, Reaven's syndrome, multiple metabolic syndrome, and metabolic cardiovascular syndrome [18, 32-34]. Several definitions for metabolic syndrome in adult populations have been proposed by different organizations including the World Health Organization (WHO), the International Diabetes Federation (IDF), the American Heart Association/National Heart, Lung, and Blood Institute (AHA/NHLBI), the National Cholesterol Education Program Adult Treatment Panel III P(NCEP-ATP
III), and the European Group for the Study of Insulin Resistance (EGIR) [15]. Although these diagnostic criteria are similar, there is variability with the different cut-off values set for each criterion. The unified criteria to diagnose metabolic syndrome include at least 3 of the following: abdominal obesity, high level of plasma triglycerides, low level of highdensity lipoprotein (HDL) cholesterol, high blood pressure, and impaired fasting glucose or insulin resistance [35].

The reported prevalence of metabolic syndrome varies depending on the diagnostic criteria opted by different studies, nonetheless the prevalence of metabolic syndrome has increased at epidemic rates for the past decade. Findings from the National Health and Nutrition Examination Survey (NHANES) 2003-2006 showed that 34\% of Americans, 20 years and older, met the criteria to be diagnosed with metabolic syndrome based on the NCEP-ATP III definition [36]. Canadian Health Measures Survey revealed that about one in five Canadian adults (20\% of the population) had metabolic syndrome [37]. No standard diagnostic criteria for metabolic syndrome in children and adolescents have been developed, which makes studying metabolic syndrome in children challenging. Nonetheless, the Third National Health and Nutrition Examination Survey (NHANES III, 1988-1994) reported on a $4.2 \%$ prevalence of metabolic syndrome among 12 - to 19-year-old American adolescents (approximately 1 million adolescents) [38]. In addition, nearly $30 \%$ of overweight adolescents met the criteria of metabolic syndrome according the definition proposed by the NCEP-ATPIII [38]. De Ferranti and colleagues reported an increase of $38 \%$ in the prevalence of metabolic syndrome in adolescents of the same age group between 1988 and 2000 using the same definition [39].

\section{Periodontal Diseases in Obesity and Metabolic Syndrome}

Periodontal diseases, a chronic inflammation by its nature, have been linked to many systemic conditions. The findings from meta-analyses suggest that cardiovascular diseases [4042] and obesity [43-45] increase the chance of destructive periodontal disease by $20 \%$ and $35 \%$, respectively. Moreover, studies on diabetic patients indicate that type 2 diabetes is a risk factor for advanced form of destruction periodontal disease [46]. Metabolic syndrome is also positively correlated with destructive periodontal disease [9-22]. A recent meta-analysis reported that the odds of destructive periodontal disease to occur was 1.71 to 2.09 higher in individuals with metabolic syndrome compared to those without this syndrome [47]. Despite all these evidence indicating the higher risk of destructive periodontal disease in obesity and metabolic syndrome, the underlying biological mechanism(s) is yet to be fully understood. Studying the common etiological factors in obesity, metabolic syndrome, and destructive periodontal disease would be a potential approach to delineate biological mechanisms explaining the higher risk of destructive periodontal disease under these conditions. Inflammation is indeed one of the common factors in the pathogenesis of destructive periodontal disease, obesity, and metabolic syndrome. Figure 1 represents 


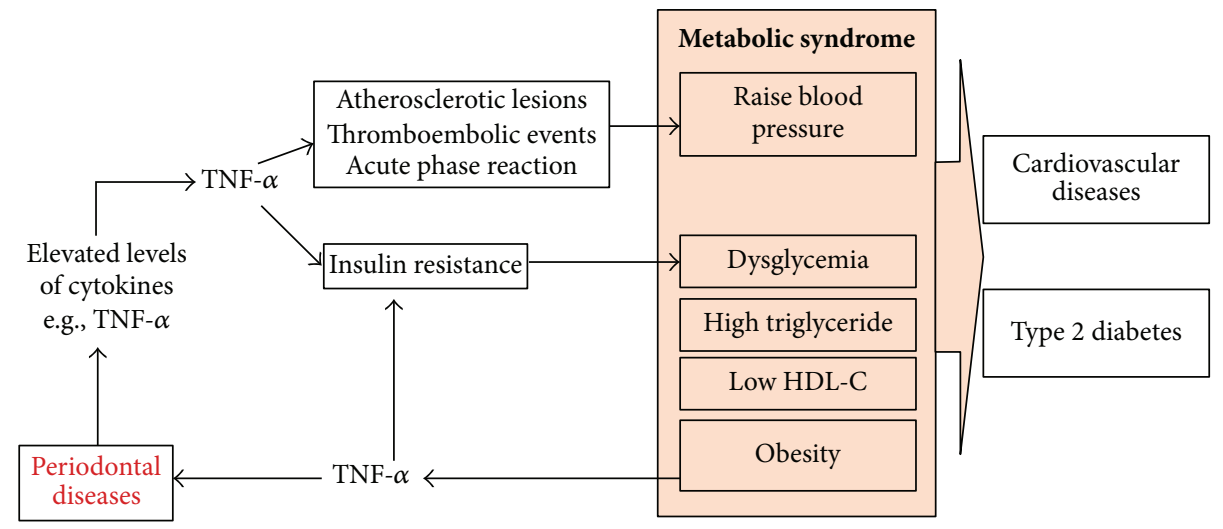

Figure 1: A biological working model on the onset of destructive periodontal disease in obesity and metabolic syndrome adapted from Nishimura et al., 2003 [8]. This scheme represents a potential working model in which the systemic elevated levels of TNF- $\alpha$ in obesity and metabolic syndrome potentially contribute to the onset and development of destructive periodontal disease. Specifically, the elevated levels of systemic inflammatory mediators, such as TNF- $\alpha$ or IL-6, in obesity or metabolic syndrome enhance the host response to periodontal pathogens hence increase the chance to develop destructive periodontal disease. In destructive periodontal disease, periodontal pathogens induce inflammation prompting the destruction of connective tissues and bone in the periodontium. The connections between destructive periodontal disease and systemic conditions, such as obesity, are complex and often multidirectional; the working model presented here is a simplified picture of these connections.

a simplified working model explaining how inflammation connects these diseases. Indeed, this working model does not exclude other potential biological mechanisms.

In this review we focus on a potential interorgan inflammatory mechanism explaining the higher prevalence of destructive periodontal disease in obesity and metabolic syndrome. Higher risk of destructive periodontal disease associated with obesity and/or metabolic syndrome is most likely bidirectional, and here we only concentrate on how obesity or metabolic syndrome induces or enhances destructive periodontal disease.

Tumor necrosis factor- $\alpha$ (TNF- $\alpha$ ) is the best candidate connecting higher destructive periodontal disease in obesity or metabolic syndrome. TNF- $\alpha$ levels are systemically elevated in both obesity and metabolic syndrome [48]. Studies on human and animal models in the 1990s indicated that adipocytes secrete TNF- $\alpha$, and hence the excess of fat in obesity leads to a systemic chronic inflammation $[49,50]$. TNF- $\alpha$ was also reported to induce insulin resistance in both diabetes and obesity [51]. It is known that other cytokines from adipose tissues also contribute to the chronic systemic inflammation in obesity [48].

TNF- $\alpha$ is one of the key periodontal pathogens-induced early inflammatory cytokines in destructive periodontal disease [52]. Elevated levels of TNF- $\alpha$ are a well-known risk factor for destruction periodontal disease [52]. Increased levels of TNF- $\alpha$ contribute to the onset of destructive periodontal disease via several mechanisms. Examples of these mechanisms are (i) TNF- $\alpha$ prompts the destruction of alveolar bone by stimulating the formation of bone-resorbing cells (osteoclasts) [53]; (ii) TNF- $\alpha$, as one of the early promoters of host response to periodontal bacterial pathogens, regulates matrix metalloproteinases (MMPs), which are capable of degrading the connective tissues. Interestingly, studies on the immune response to periodontal pathogens showed that
TNF- $\alpha$ enhanced the immune response to these pathogens [54]. Previous studies on human subjects reported on the elevated levels of TNF- $\alpha$ in gingival crevicular fluid (GCF) of obese individuals. The authors reported on a $0.74 \mathrm{pg}$ increase in GCF TNF- $\alpha$ with an increase of one BMI unit. 32 obese subjects aged between 13 and 24 years was recruited in this study [55]. In a larger scale study on the third National Health and Nutrition Examination Survey (NHANES II) dataset, Genco and colleagues showed that serum TNF- $\alpha$ levels were not correlated with the severity of destructive periodontal disease in BMI over $30 \mathrm{~kg} / \mathrm{m}$, and proposed the notion that TNF- $\alpha$ mainly contributes to the initial stage of destructive periodontal disease development [56]. In addition, our group has been investigated the potential development of destructive periodontal disease in children at risk of obesity and metabolic syndrome as they age. We are studying the Oral Health component within a cohort of 600 children in Quebec (the Quebec Adipose and Lifestyle Investigation in Youth; QUALITY cohort), which aims to investigate the natural history of obesity and its vascular and metabolic consequences [57]. Our results from the baseline visit of the QUALITY cohort so far indicate that obese boys, but not girls, have $37 \%$ higher levels of TNF- $\alpha$, a risk factor for destructive periodontal disease, in their gingival crevicular fluid (GCF) compared to nonobese boys [58]. We also found that metabolic syndrome in boys was associated with 49 percent increase in the levels of TNF- $\alpha$ in gingiva crevicular fluid (Ka et al.; unpublished data).

The second candidate explaining a mechanism for the higher prevalence of destructive periodontal diseases in obesity or metabolic syndrome is interleukin 6 (IL-6). IL6 is a multifunctional cytokine produced by variety of cells including macrophages, neutrophils, and endothelial cells (reviewed in [59]). The double edge effects (i.e., pro- and antiinflammatory) of IL- 6 create a complexity in investigating its 
roles in normal or diseased conditions [59]. IL-6 systemic and GCF levels increase in destructive periodontal diseases (reviewed in [60]). Additionally, controversial studies suggested an increase or no change in serum IL-6 levels in obesity and metabolic syndrome (reviewed in [61]). Unfortunately, to the best of our knowledge, no evidence from animal or human studies supports the hypothetical model in which obesity or metabolic syndrome-induced IL- 6 increases the risk of destructive periodontal disease.

Taken together, these evidence support the notion that, in obesity and metabolic syndrome, the elevated levels of TNF$\alpha$, and possibly IL-6, may increase the chance of destructive periodontal diseases development, which could be directly through mechanisms discussed earlier and also indirectly by enhancing the bacterial-induced host immune response in obesity and metabolic syndrome.

\section{Conclusion}

The obesity epidemic in North America and worldwide is an alarming public health issue. The prevalence of childhood obesity and overweight is rising rapidly in Canada [62, 63]. The total direct costs attributable to overweight and obesity in Canada was $\$ 6.0$ billion in 2006, representing $4.1 \%$ of the total health expenditures in the country [64]. Similarly, data from American adults showed an increase in the prevalence of metabolic syndrome from 24 to 27\% between 1988-1994 and 1999-2000 [65]. Similar trends were seen in American adolescents particularly in overweight and obese subjects, for whom the prevalence of metabolic syndrome was 32.1\% [32]. Moreover, higher health care cost with increased number of metabolic syndrome components has been reported [66-68]. The annual health care cost associated for an individual with 1 component was estimated to be $\$ 5564$ compared to $\$ 12,287$ for someone with 4 components [68].

Understanding the multidirectional and dynamic links among obesity, metabolic syndrome, and destructive periodontal disease can improve current preventive and therapeutic modalities for these conditions. For example, one could screen the GCF TNF- $\alpha$ levels of obese individuals to identify a subgroup of obese subjects, who are more susceptible to develop destructive periodontal disease.

\section{Authors' Contribution}

Roozbeh Khosravi and Khady Ka equally contributed to this publication.

\section{Acknowledgments}

The authors acknowledge the generous assistance of Dr. Martin Kim for revising preliminary drafts of this paper. They mourn the loss of their colleague and leader, Dr. Marie Lambert, Principal Investigator of the QUALITY cohort. Also they wish to acknowledge the contributions from all investigators, staff, and patients of the QUALITY cohort. Our team has been financially supported in part by research funding from the Fonds de Recherche du Québec-Santé (FRQ-S), Canadian Institutes of Health Research (CIHR), Network for
Oral and Bone Health Research, Canada Research Chairs (CRC), and McGill University Faculty of Dentistry.

\section{References}

[1] B. L. Pihlstrom, B. S. Michalowicz, and N. W. Johnson, "Periodontal diseases," The Lancet, vol. 366, no. 9499, pp. 1809-1820, 2005.

[2] C. L. Drisko, D. L. Cochran, T. Blieden et al., "Position paper: sonic and ultrasonic scalers in periodontics. Research, Science and Therapy Committee of the American Academy of Periodontology," Journal of Periodontology, vol. 71, no. 11, pp. 1792-1801, 2000.

[3] T. E. Van Dyke and D. Sheilesh, "Risk factors for periodontitis," Journal of the International Academy of Periodontology, vol. 7, no. 1, pp. 3-7, 2005.

[4] S. Offenbacher, S. Lieff, K. A. Boggess et al., "Maternal periodontitis and prematurity. Part I: obstetric outcome of prematurity and growth restriction," Annals of Periodontology, vol. 6, no. 1, pp. 164-174, 2001.

[5] F. A. Scannapieco, R. B. Bush, and S. Paju, "Associations between periodontal disease and risk for atherosclerosis, cardiovascular disease, and stroke. A systematic review," Annals of Periodontology, vol. 8, no. 1, pp. 38-53, 2003.

[6] G. W. Taylor, "Bidirectional interrelationships between diabetes and periodontal diseases: an epidemiologic perspective," Annals of Periodontology, vol. 6, no. 1, pp. 99-112, 2001.

[7] M. Alabdulkarim, N. Bissada, M. Al-Zahrani, A. Ficara, and B. Siegel, "Alveolar bone loss in obese subjects," Journal of the International Academy of Periodontology, vol. 7, no. 2, pp. 3438, 2005.

[8] F. Nishimura, Y. Iwamoto, J. Mineshiba, A. Shimizu, Y. Soga, and Y. Murayama, "Periodontal disease and diabetes mellitus: the role of tumor necrosis factor- $\alpha$ in a 2 -way relationship," Journal of Periodontology, vol. 74, no. 1, pp. 97-102, 2003.

[9] C. Benguigui, V. Bongard, J.-B. Ruidavets et al., "Metabolic syndrome, insulin resistance, and periodontitis: a cross-sectional study in a middle-aged French population," Journal of Clinical Periodontology, vol. 37, no. 7, pp. 601-608, 2010.

[10] P. K. D. O. Borges, S. G. A. Gimeno, N. E. Tomita et al., "Prevalence and characteristics associated with metabolic syndrome in Japanese-Brazilians with and without periodontal disease," Cadernos de Saude Publica, vol. 23, no. 3, pp. 657-668, 2007.

[11] F. D'Aiuto, W. Sabbah, G. Netuveli et al., "Association of the metabolic syndrome with severe periodontitis in a large U.S. population-based survey," Journal of Clinical Endocrinology and Metabolism, vol. 93, no. 10, pp. 3989-3994, 2008.

[12] D.-H. Han, S.-Y. Lim, B.-C. Sun, D. Paek, and H.-D. Kim, “The association of metabolic syndrome with periodontal disease is confounded by age and smoking in a Korean population: the Shiwha-Banwol environmental health study," Journal of Clinical Periodontology, vol. 37, no. 7, pp. 609-616, 2010.

[13] Y. S. Khader, B. Khassawneh, B. Obeidat et al., "Periodontal status of patients with metabolic syndrome compared to those without metabolic syndrome," Journal of Periodontology, vol. 79, no. 11, pp. 2048-2053, 2008.

[14] M. Kushiyama, Y. Shimazaki, and Y. Yamashita, "Relationship between metabolic syndrome and periodontal disease in japanese adults," Journal of Periodontology, vol. 80, no. 10, pp. 1610-1615, 2009. 
[15] Y.-E. Kwon, J.-E. Ha, D.-I. Paik, B.-H. Jin, and K.-H. Bae, “The relationship between periodontitis and metabolic syndrome among a Korean nationally representative sample of adults," Journal of Clinical Periodontology, vol. 38, no. 9, pp. 781-786, 2011.

[16] P. Li, L. He, Y.-Q. Sha, and Q.-X. Luan, "Relationship of metabolic syndrome to chronic periodontitis," Journal of Periodontology, vol. 80, no. 4, pp. 541-549, 2009.

[17] T. Morita, Y. Yamazaki, A. Mita et al., "A cohort study on the association between periodontal disease and the development of metabolic syndrome," Journal of Periodontology, vol. 81, no. 4, pp. 512-519, 2010.

[18] L. Nibali, F. D’Aiuto, G. Griffiths, K. Patel, J. Suvan, and M. S. Tonetti, "Severe periodontitis is associated with systemic inflammation and a dysmetabolic status: a case-control study," Journal of Clinical Periodontology, vol. 34, no. 11, pp. 931-937, 2007.

[19] M. M. Pozharitskaia, T. G. Simakova, L. K. Starosel'tseva, and V. V. Kirienko, "Inflammatory diseases of the parodontium in patiens with metabolic syndrome," Stomatologiia, vol. 83, no. 6 , pp. 13-16, 2004.

[20] T. Saito, Y. Shimazaki, Y. Kiyohara et al., "The severity of periodontal disease is associated with the development of glucose intolerance in non-diabetics: the hisayama study," Journal of Dental Research, vol. 83, no. 6, pp. 485-490, 2004.

[21] Y. Shimazaki, T. Saito, K. Yonemoto, Y. Kiyohara, M. Iida, and Y. Yamashita, "Relationship of metabolic syndrome to periodontal disease in Japanese women: the hisayama study," Journal of Dental Research, vol. 86, no. 3, pp. 271-275, 2007.

[22] P. Timonen, M. Niskanen, L. Suominen-Taipale, A. Jula, M. Knuuttila, and P. Ylöstalo, "Metabolic syndrome, periodontal infection, and dental caries," Journal of Dental Research, vol. 89, no. 10, pp. 1068-1073, 2010.

[23] M. S. Al-Zahrani, N. F. Bissada, and E. A. Borawski, "Obesity and periodontal disease in young, middle-aged, and older adults," Journal of Periodontology, vol. 74, no. 5, pp. 610-615, 2003.

[24] WHO, Unhealthy Diets \& Physical Inactivity, World Health Organization, 2009.

[25] M. Shields, M. D. Carroll, and C. L. Ogden, "Adult obesity prevalence in Canada and the United States," NCHS Data Brief, no. 56, pp. 1-8, 2011.

[26] Health Canada, Canadian Guidelines for Body Weight Classification in Adults, 2003.

[27] M. Tjepkema, "Adult obesity," Health Reports, vol. 17, no. 3, pp. 9-25, 2006.

[28] WHO, Obesity and Overweight, World Health Organization, 2010.

[29] M. Shields, Nutrition: Findings From the Canadian Community Health Survey, Statistics Canada Publication, Ottawa, Canada, 2005.

[30] D. P. Guh, W. Zhang, N. Bansback, Z. Amarsi, C. L. Birmingham, and A. H. Anis, "The incidence of co-morbidities related to obesity and overweight: a systematic review and meta-analysis," BMC Public Health, vol. 9, article 88, 2009.

[31] International Diabetes Federation, The IDF Concensus Definition of the Metabolic Syndrome in Children and Adolescents, 2007.

[32] G. E. Duncan, S. M. Li, and X.-H. Zhou, "Prevalence and trends of a metabolic syndrome phenotype among U.S. adolescents, 1999-2000," Diabetes Care, vol. 27, no. 10, pp. 2438-2443, 2004.
[33] I. Hjermann, "The metabolic cardiovascular syndrome: syndrome X, Reaven's syndrome, insulin resistance syndrome, atherothrombogenic syndrome," Journal of Cardiovascular Pharmacology, vol. 20, no. 8, pp. S5-S10, 1992.

[34] A. D. Liese, E. J. Mayer-Davis, and S. M. Haffner, "Development of the multiple metabolic syndrome: an epidemiologic perspective," Epidemiologic Reviews, vol. 20, no. 2, pp. 157-172, 1998.

[35] K. G. M. M. Alberti, R. H. Eckel, S. M. Grundy et al., "Harmonizing the metabolic syndrome: a joint interim statement of the international diabetes federation task force on epidemiology and prevention; National heart, lung, and blood institute; American heart association; World heart federation; International atherosclerosis society; and international association for the study of obesity," Circulation, vol. 120, no. 16, pp. 1640-1645, 2009.

[36] R. B. Ervin, "Prevalence of metabolic syndrome among adults 20 years of age and over, by sex, age, race and ethnicity, and body mass index: United States, 2003-2006," National Health Statistics Reports, no. 13, pp. 1-7, 2009.

[37] N. D. Riediger and I. Clara, "Prevalence of metabolic syndrome in the Canadian adult population," Canadian Medical Association Journal, vol. 183, no. 15, pp. E1127-E1134, 2011.

[38] S. Cook, M. Weitzman, P. Auinger, M. Nguyen, and W. H. Dietz, "Prevalence of a metabolic syndrome phenotype in adolescents: findings from the third National Health and Nutrition Examination Survey, 1988-1994," Archives of Pediatrics and Adolescent Medicine, vol. 157, no. 8, pp. 821-827, 2003.

[39] S. D. De Ferranti, K. Gauvreau, D. S. Ludwig, J. W. Newburger, and N. Rifai, "Inflammation and changes in metabolic syndrome abnormalities in US adolescents: findings from the 19881994 and 1999-2000 National Health and Nutrition Examination Surveys," Clinical Chemistry, vol. 52, no. 7, pp. 1325-1330, 2006.

[40] S.-J. Janket, A. E. Baird, S.-K. Chuang, and J. A. Jones, "Metaanalysis of periodontal disease and risk of coronary heart disease and stroke," Oral Surgery, Oral Medicine, Oral Pathology, Oral Radiology, and Endodontics, vol. 95, no. 5, pp. 559-569, 2003.

[41] Y. S. Khader, Z. S. M. Albashaireh, and M. A. Alomari, "Periodontal diseases and the risk of coronary heart and cerebrovascular diseases: a meta-analysis," Journal of Periodontology, vol. 75, no. 8, pp. 1046-1053, 2004.

[42] Z. You, M. Cushman, N. S. Jenny, and G. Howard, "Tooth loss, systemic inflammation, and prevalent stroke among participants in the reasons for geographic and racial difference in stroke (REGARDS) study," Atherosclerosis, vol. 203, no. 2, pp. 615-619, 2009.

[43] B. W. Chaffee and S. J. Weston, "Association between chronic periodontal disease and obesity: a systematic review and metaanalysis," Journal of Periodontology, vol. 81, no. 12, pp. 1708-1724, 2010.

[44] J. Katz and E. Bimstein, "Pediatric obesity and periodontal disease: a systematic review of the literature," Quintessence International, vol. 42, no. 7, pp. 595-599, 2011.

[45] J. Suvan, F. D’Aiuto, D. R. Moles, A. Petrie, and N. Donos, "Association between overweight/obesity and periodontitis in adults. A systematic review," Obesity Reviews, vol. 12, no. 501, pp. e381-e404, 2011.

[46] N. G. M. Chávarry, M. V. Vettore, C. Sansone, and A. Sheiham, "The relationship between diabetes mellitus and destructive periodontal disease: a meta-analysis," Oral Health \& Preventive Dentistry, vol. 7, no. 2, pp. 107-127, 2009. 
[47] L. Nibali, N. Tatarakis, I. Needleman et al., "Association between metabolic syndrome and periodontitis: a systematic review and meta-analysis," Journal of Clinical Endocrinology and Metabolism, vol. 98, no. 3, p. 913, 2013.

[48] M. F. Gregor and G. S. Hotamisligil, "Inflammatory mechanisms in obesity," Annual Review of Immunology, vol. 29, pp. 415-445, 2011.

[49] G. S. Hotamisligil, N. S. Shargill, and B. M. Spiegelman, "Adipose expression of tumor necrosis factor- $\alpha$ : direct role in obesity-linked insulin resistance," Science, vol. 259, no. 5091, pp. 87-91, 1993.

[50] G. S. Hotamisligil, P. Arner, J. F. Caro, R. L. Atkinson, and B. M. Spiegelman, "Increased adipose tissue expression of tumor necrosis factor- $\alpha$ in human obesity and insulin resistance," The Journal of Clinical Investigation, vol. 95, no. 5, pp. 2409-2415, 1995.

[51] G. S. Hotamisligil and B. M. Spiegelman, "Tumor necrosis factor $\alpha$ : a key component of the obesity-diabetes link," Diabetes, vol. 43, no. 11, pp. 1271-1278, 1994.

[52] D. T. Graves and D. Cochran, "The contribution of interleukin1 and tumor necrosis factor to periodontal tissue destruction," Journal of Periodontology, vol. 74, no. 3, pp. 391-401, 2003.

[53] K. Kobayashi, N. Takahashi, E. Jimi et al., "Tumor necrosis factor $\alpha$ stimulates osteoclast differentiation by a mechanism independent of the ODF/RANKL-RANK interaction," Journal of Experimental Medicine, vol. 191, no. 2, pp. 275-285, 2000.

[54] D. T. Graves, R. Liu, M. Alikhani, H. Al-Mashat, and P. C. Trackman, "Diabetes-enhanced inflammation and apoptosisimpact on periodontal pathology," Journal of Dental Research, vol. 85, no. 1, pp. 15-21, 2006.

[55] M. Lundin, T. Yucel-Lindberg, G. Dahllöf, C. Marcus, and T. Modéer, "Correlation between TNF $\alpha$ in gingival crevicular fluid and body mass index in obese subjects," Acta Odontologica Scandinavica, vol. 62, no. 5, pp. 273-277, 2004.

[56] R. J. Genco, S. G. Grossi, A. Ho, F. Nishimura, and Y. Murayama, "A proposed model linking inflammation to obesity, diabetes, and periodontal infections," Journal of Periodontology, vol. 76, no. 11, pp. 2075-2084, 2005.

[57] M. Lambert, A. Van Hulst, J. O’Loughlin et al., "Cohort profile: the quebec adipose and lifestyle investigation in youth cohort," International Journal of Epidemiology, vol. 41, pp. 1533-1544, 2012.

[58] R. Khosravi, S. D. Tran, M. Lambert et al., "Adiposity and gingival crevicular fluid tumour necrosis factor- $\alpha$ levels in children," Journal of Clinical Periodontology, vol. 36, no. 4, pp. 301-307, 2009.

[59] T. Kishimoto, "Interleukin-6: discovery of a pleiotropic cytokine," Arthritis Research and Therapy, vol. 8, no. 2, 2006.

[60] L. Nibali, S. Fedele, F. D’Aiuto, and N. Donos, "Interleukin-6 in oral diseases: a review," Oral Diseases, vol. 18, no. 3, pp. 236-243, 2012.

[61] K. Eder, N. Baffy, A. Falus, and A. K. Fulop, "The major inflammatory mediator interleukin-6 and obesity," Inflammation Research, vol. 58, no. 11, pp. 727-736, 2009.

[62] S. Amar and X. Han, "The impact of periodontal infection on systemic diseases," Medical Science Monitor, vol. 9, no. 12, pp. RA291-RA299, 2003.

[63] M. S. Tremblay and J. D. Willms, "Secular trends in the body mass index of Canadian children," Canadian Medical Association Journal, vol. 163, no. 11, pp. 1429-1433, 2000.
[64] A. H. Anis, W. Zhang, N. Bansback, D. P. Guh, Z. Amarsi, and C. L. Birmingham, "Obesity and overweight in Canada: an updated cost-of-illness study," Obesity Reviews, vol. 11, no. 1, pp. 31-40, 2010.

[65] E. S. Ford, W. H. Giles, and A. H. Mokdad, "Increasing prevalence of the metabolic syndrome among U.S. adults," Diabetes Care, vol. 27, no. 10, pp. 2444-2449, 2004.

[66] D. M. Boudreau, D. C. Malone, M. A. Raebel et al., "Health care utilization and costs by metabolic syndrome risk factors," Metabolic Syndrome and Related Disorders, vol. 7, no. 4, pp. 305313, 2009.

[67] G. A. Nichols and E. J. Moler, "Metabolic syndrome components are associated with future medical costs independent of cardiovascular hospitalization and incident diabetes," Metabolic Syndrome and Related Disorders, vol. 9, no. 2, pp. 127-133, 2011.

[68] L. Tamariz, A. Palacio, Y. Yang, D. Parris, R. Ben-Joseph, and H. Florez, "Health economics perspective of the components of the cardiometabolic syndrome," Journal of Clinical Hypertension, vol. 12, no. 7, pp. 549-555, 2010. 


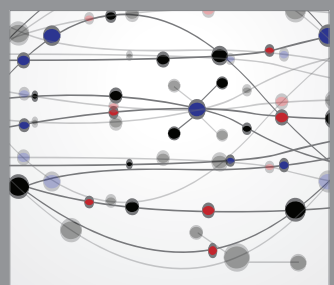

The Scientific World Journal
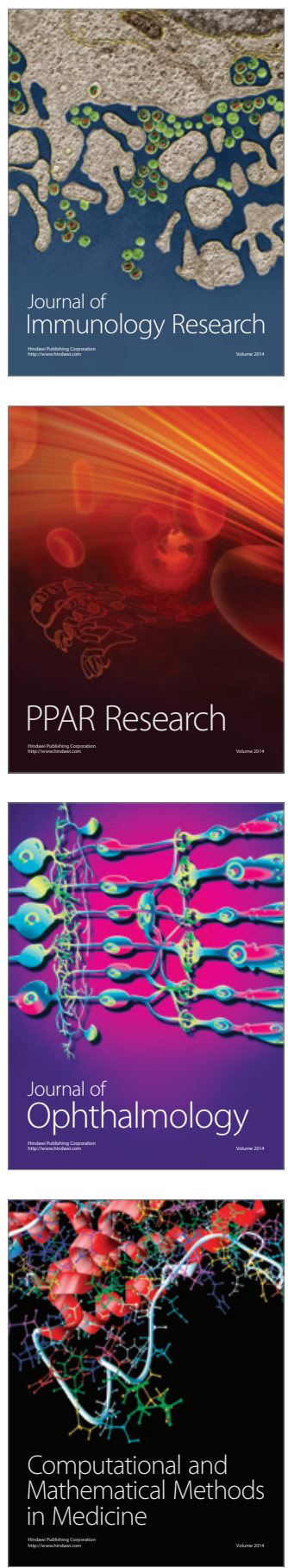

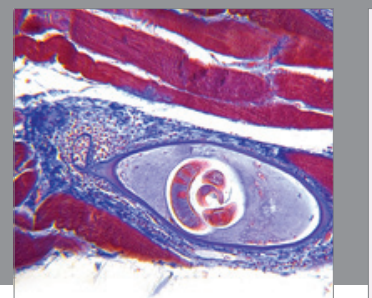

Gastroenterology

Research and Practice
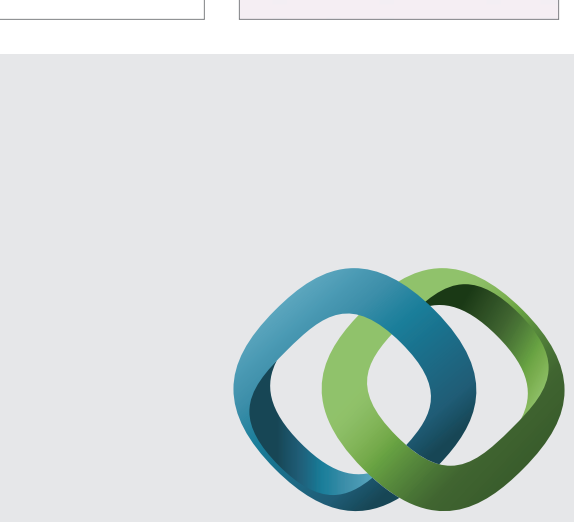

\section{Hindawi}

Submit your manuscripts at

http://www.hindawi.com
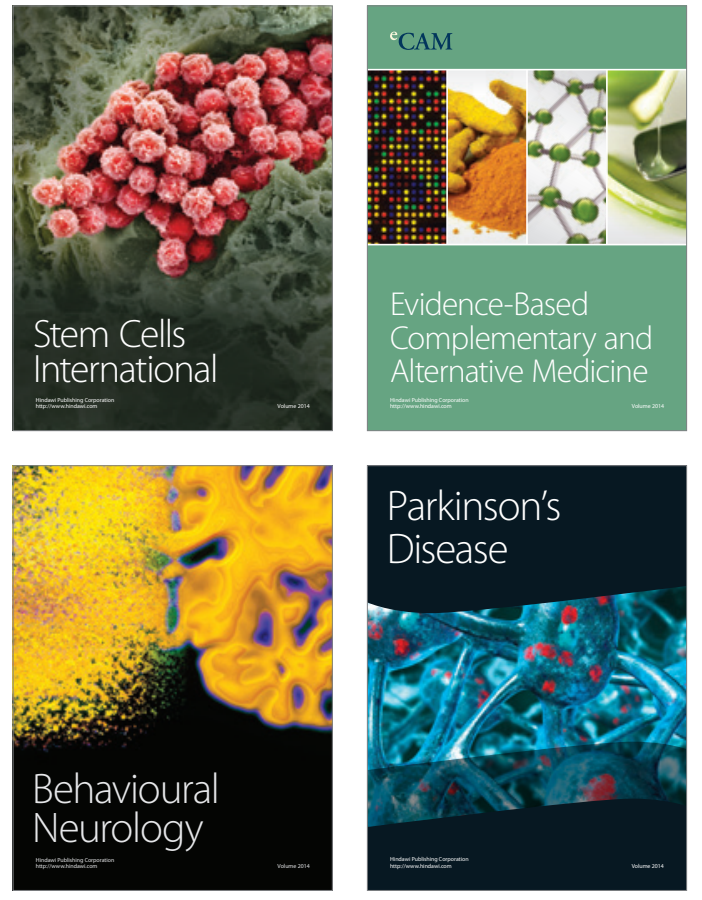
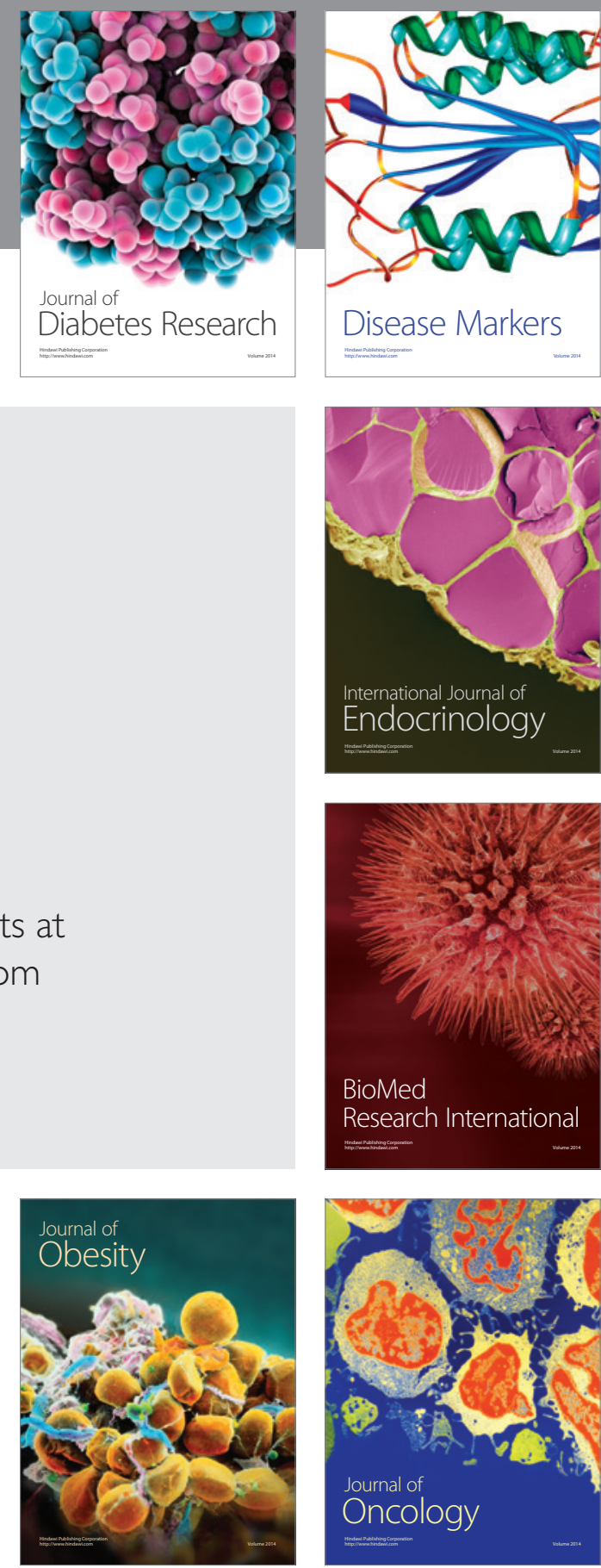

Disease Markers
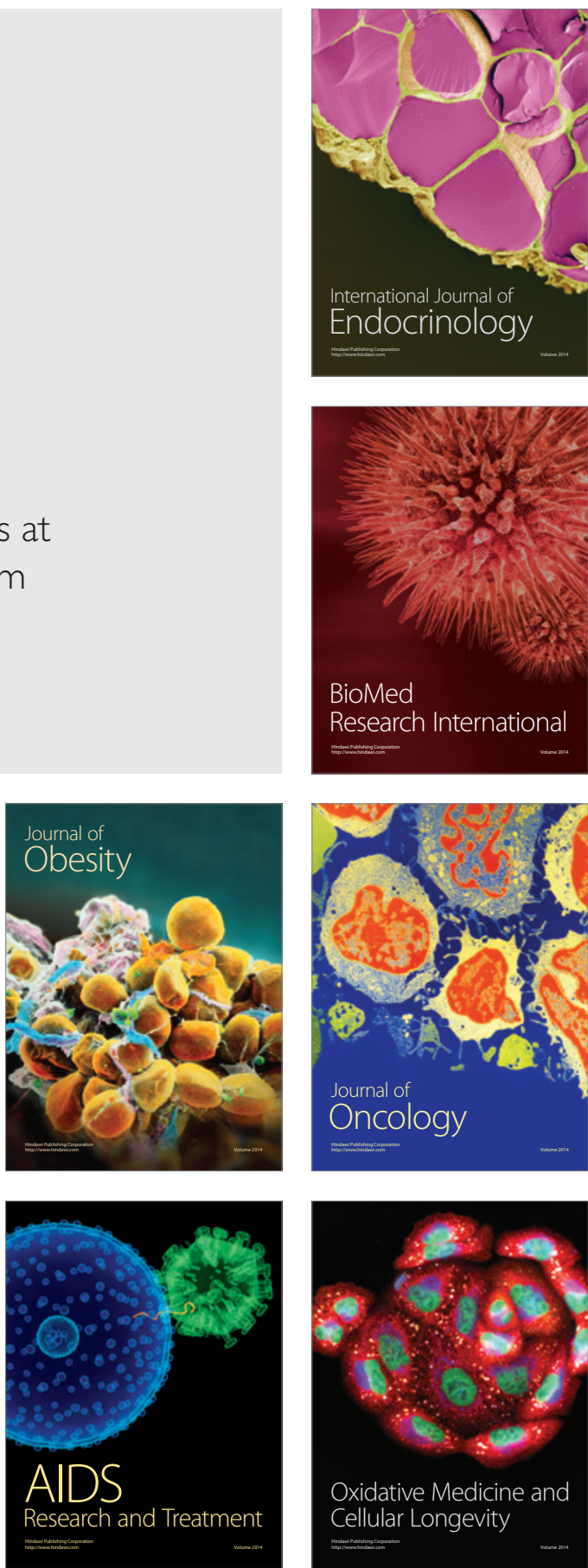